\title{
Prevalence of depression among physicians: A comprehensive meta-analysis
}

\author{
Andreea Raluca Adam, Florinda Tinela Golu \\ Faculty of Psychology and Educational Sciences, University of Bucharest, Romania
}

\begin{abstract}
Depression among medical personnel is recognized worldwide as a serious problem, yet quantitative syntheses of prevalence studies are rare. We proceeded quantify and understand prevalence variation among physicians at the global levels.

For this meta-analysis, we searched 6 databases, including: PsycINFO, Web of Science, PubMed, ProQuest using a comprehensive search strategy to identify prevalence of the physicians' depression studies in the literature, published from inception of 1979. Studies reporting estimates of depression prevalence in physicians were included in the analyses. Studies quality was assessed with a prevalence risk of bias tool. Meta-regression was used to explore heterogeneity of the moderators we included in the analysis.

Of the 3,156 studies initially identified, 33 were eligible for inclusion. These studies were geographically diverse (15 countries). The pooled prevalence rate for overall elder abuse was .243 (CI [.188; .306]; p<.001). Meta-analysis of studies that included overall abuse revealed heterogeneity. Significant associations were found between overall prevalence estimates and region, but not for sampling allocation and severity of depression.

In this meta-analysis, the summary estimate of the prevalence of depression among physicians is $24.3 \%$, ranging from $2 \%$ to $65.3 \%$ depending on the region from the studies.

Further research is needed to identify effective strategies for preventing and treating depression among physicians.
\end{abstract}

Keywords: depression, physicians, depression prevalence, meta-analysis, mental health

\section{INTRODUCTION}

Being a physician is often thought as one of the most rewarding, respectable and safety professions, but it is also known to be one of the most stressful with high probability of long-term negative impact on the physician's mental health and wellbeing. Medical profession is exposed to many stressors, such as the burden imposed by expectations of a high degree of professionalism, responsibility for patients' healthcare and for an efficient communication with these, as well as the maintenance of a good relationship colleagues and concerns about medical errors and malpractice litigation. On the other hand, hardworking bureaucracy, large workload, irregular working hours, competitiveness of training programs, pressure of patient and service demands and poor work-life balance are factors that explain the elevated prevalence of mental disorder and depression among physicians $(1,2)$. Evidence shows the common mental health issues that physicians are struggling with are burnout (3), anxiety (4), depression and suicidal ideation $(5,6)$. Although depression and mental health status is a current concern in broad domains, actual research of occupational health brings evidence regarding higher prevalence of common mental disorders among physicians compared with the general population (4) and other professions $(7,8)$.

In addition, prevalence rates of depression vary across gender, medical specialty, geographical location, age and other variables. Many studies showed that as physicians' prevalence of depression has 
higher rates the first years of practice, compared to those who passed the residency $(9,10)$ and prevalence of depression among rural doctors is higher than among those from urban areas (11). Women doctors tend to be more depressed than male doctors $(12,13)$ and is more likely that specialties with higher level of energy consuming and additional stress (i.e. emergency, oncology) to have elevated rates of depression $(14,15)$. However, the prevalence of depressive symptoms has been inconsistent across studies. For example, the prevalence estimates among physicians is in the range between $20 \%$ and $29.9 \%$ for medical students $(3,16)$; between $20 \%$ and $39 \%$ for residents, fellows and interns $(17,18,19)$; and finally for physicians the range of depression prevalence is between $10 \%$ to $59 \%$ $(20,21)$. Moreover, a significant amount of studies reports a cumulative prevalence of depression for all levels of medical training (i.e. residents and physicians; students, residents and physicians or nurses and physicians) $(22,23)$.

Given these inconsistencies, a reliable estimate of the prevalence of depression could enable us to understand the basic information about depression among this population and severity of the depression. However, as far as we know, from this field, only one meta-analytic study focused on prevalence of depression among resident physicians (24), which bring comprehensive understanding about depression in medical domain. As literature shows, there is a significant difference between these groups of medical professions: physicians, residents/trainees and students, this is why, our paper expands the systematic reviews, by evaluating the prevalence of depression only to physicians who passed the residency level. Therefore, the first objective of this meta-analysis is to address this gap in the literature and to provide a quantitative analyze of the available data of the cross-sectional studied, regarding the prevalence of depression among physicians, followed by a second objective, to investigate the impact of region regarding the prevalence, as well as the impact of studies' sampling and severity of depression.

Awareness of the real rates of depression among physicians as well as the effects they are likely to be on individuals, families, and the health service more broadly (25) including quality of patient healthcare and profession errors $(26,27)$. This evaluation of the evidence base yells the real necessity for action regarding the mental disorders of physicians, a demand for a greater focus on physicians' mental health within training programs, a new crafting of workplaces and organizational support.

On the other hand, there are broader systemic issues in medicine practice such as stigma, regulatory practices, and concerns around confidentiality and registration, that also affect the context physicians might act to help-seeking or disclosure through traditional pathways. These features make physicians a unique population and suggest that the type of approach might differ from other groups.

\section{METHOD}

\section{Search strategy}

Studies were collected through searches of electronic databases PsycINFO, Web of Science, PubMed, ProQuest, from the incept of 1989 to December 2019. A search strategy was developed for each database with a combination of free text and MeSH terms for controlling vocabulary. The following comprehensive search string was entered into the databases: "doctor*” OR "medical professionals" OR "medical practitioner*” OR "physician*” AND "depression" OR "mental health" OR "mental state" AND "prevalence" OR "incidence" OR "rate". Also, it was manually searching for citations in reference lists of the relevant articles and additional webbased search on Google Scholar for grey literature. The search was limited to those published in English language and human science, and each study from the final results was screened by title and abstract.

\section{Selection and eligibility criteria}

The selected studies were screened in two stages: screening of titles and abstracts followed by the retrieval and screening of full-text articles using the eligibility criteria recommended by the Preferred Reporting Items for Systematic Reviews and Meta-Analyses (PRISMA) (28) in Figure 1. If more than one publication reported on a single study, the study that provided the most relevant data was selected for the meta-analytic final analysis.

Studies were included if they were applying the following conditions: the population of interest comprised physicians of any specialty, working in primary, secondary, or tertiary care settings; studies that clearly delimited the population if interest from others (i.e. nurses, residents, interns, trainees, fellows, students or auxiliary personnel). Therefore, studies that did not report prevalence separately (i.e. nurses vs. physicians, residents vs. physicians) were excluded; studies that reported estimates prevalence of depression at a national or region level (i.e. provinces, districts or cities); studies reported the prevalence of depression of the physicians at any severity level, by any method of assessment (i.e. interview, assessment tool) or by any period of presence of the depression (i.e. current or history); studies with cross-sectional design. 


\section{Risk of bias}

The quality assessment of the studies was performed with Risk of Bias Tool (29) designed to assess population-based prevalence studies. The tool assesses the study methodological quality in terms of both external and internal validity by examining:

External validity with four items: Was the study's target population a close representation of the national population?; Was the sampling frame a true or close representation of the target population?; Was some form of random selection used to select the sample, or was a census undertaken?; Was the likelihood of non-response bias minimal?

Internal validity has six items as follows: Were data collected directly from the subjects (as opposed to a proxy)?; Was an acceptable case definition used in the study?; Was the study instrument that measured the parameter of interest shown to have reliability and validity?; Was the same mode of data collection used for all subjects?; Was the length of the shortest prevalence period for the parameter of interest appropriate?; Were the numerator(s) and denominator(s) for the parameter of interest appropriate?

Each of the studies was rated into dichotomous ratings: low risk and high risk. An overall score was calculated by summing all the items rated with low risk. Thus, higher scores indicated lower risk of bias and stronger method quality (see Table 2) as it follows: 8 or more "yes" answers - low risk of bias; 6 to 7 "yes" answers - moderate risk of bias; and 5 or fewer "yes" answers - high risk of bias.

\section{Moderator variables}

We conducted categorial moderator analyses testing the following variables: depression severity, region and design. Severity of depression refers to the level of the symptomatology that every study report and it is clustered by the following data reports: unknown - for the studies that do not present any data of depression level; low - for the data that report depression as symptoms, troublesome, borderline, tendency, at risk or mild; medium - for data that present depression as clinical, positive at screening, moderate, mild-to-moderate; high - for depression that is presented as major, extreme, severe or moderate-to-severe.

The second moderator, region, is clustered by geographical location and regional classification of the studies, according to World Health Organization (WHO) regions (30). One study country (31) is not part of WHO classification and could not be assigned to any WHO classification and it is named as Other.

The third moderator variable, design, refers to the sampling procedure, randomized or convenience sampling.

\section{Meta-analytic procedures}

Meta-analysis was conducted to synthesize the prevalence estimate for depression among physicians and its moderator variables. Statistical analysis based on pooled estimate of prevalence rates were calculated from raw data of number of cases with depression and study sample. The pooled estimates were calculated using DerSimonian and Laird's method for random, rather than fixed effects models, given it is likely that the true prevalence rate varies from study to study (32). All analyses were done using Comprehensive Meta-Analysis (CMA) V3. Software (33). Furthermore, the proportion depressed physicians will be transformed into a logit event rate effect size with a corresponding standard error (34). We calculated the pooled estimates and the $95 \%$ confidence interval (CI) and considered non-overlapping CIs as an indication of statistically significant differences. To determine the extent of variation between the studies, we did heterogeneity tests with Higgins' $\mathrm{I}^{2} \mathrm{I}^{2}$ statistic to measure what proportion of the variance in observed effects reflects variation in true effect (32). We did not classify $\mathrm{I}^{2} \mathrm{I}^{2}$ as low, moderate or high, considered it as being a mistake. $\mathrm{I}^{2} \mathrm{I}^{2}$ is a proportion, not an index of absolute dispersion, therefore it cannot specify about the amount of variance (35). For example - in our case - a higher value of $\mathrm{I}^{2} \mathrm{I}^{2}$ corresponds to a smaller amount of dispersion.

We did not proceed to inspect the funnel plots and assess both the degree of publication bias and its effect on the study findings. The Duval and Tweedie's Trim and Fill method is not applicable in prevalence meta-analysis. There is no need to test if a prevalence value is significantly different from any other value, therefore the probability that a prevalence study is not published just because it is not statistically significant makes no sense (35).

Subgroup analyses were performed to investigate the sources of heterogeneity and meta-regression. These analyses tested individual associations between the pooled estimates using categorical covariates: severity coded as low, moderate and high; region coded in conformity with WHO classification; and design coded as random or convenience. Covariates were entered into a multivariate meta-regression model.

\section{RESULTS}

\section{Characteristics of included studies}

Of the 3,156 studies, 2,220 potentially relevant full-text articles were screened by title and abstract. From these, we identified 131 that that have had the potential to provide data on depressive prevalence among physicians and were full text assessed. 
Among these, 27 examined other prevalence in correlation with other variables, 38 provided an overall prevalence data a mix of medical population (i.e. nurses and physicians; residents and physicians; students, residents and physicians), 21 had a different design as systematic review or randomized controlled trial, 10 studies had lack of prevalence data, and two studies were published in different journal with a slightly different title but with same study sample and outcome. After excluding ineligible studies, 33 studies that provided the inclusion criteria data were included in the qualitative and quantitative processes as shows Figure 1.

The 33 studies selected for meta-analysis were geographically diverse and included 15 countries, clustered in 4 WHO regions: two studies as Eastern Mediterranean Region; 14 studies as European Region; 8 studies as Region of the Americas; 8 studies as Western Pacific; and one study coded as Other because Taiwan is not part of any WHO region classification. Moreover, 10 studies had randomized samples and the rest of them had convenience sample. The severity of depression that we identified was: 8 studies with high depression; 10 studies with moderate depression; 7 studies with low depression; and 8 studies in which we could not identify information about the lever of depression.

From the total of 64,691 participants, 18,762 were allocated randomly, 20,721 participants were from the Europe region and 10,987 were assessed as depressed physicians at different levels of severity.

\section{Risk of bias of the included studies}

The quality of each study was assessed Figure 2. A maximum quality score of 9 was achieved in 1 of the 33 studies; 14 studies were scored as low risk of bias; 15 studies were scored as moderate; and 4 as high risk of bias. Regarding to external validity, the majority of studies used a convenience sampling (n $=22)$ and almost half of samples $(n=14)$ have a likelihood of less than $75 \%$ of non-participation. The internal validity source of risk of bias was provided by 23 studies with no refer of the lowest level of depression; and 11 studies did not specify a standard criterion for depression. Overall, $12 \%$ of the studies have a high risk of bias.

\section{Prevalence of depression among physicians}

The main meta-analytical results are displayed in Figure 3. The prevalence of depression varied substantially among studies, from $2.0 \%$ (CI [.018$.022] ; \mathrm{p}<0001$ ) to $65.3 \%$ (CI [.628-.676]; $\mathrm{p}<0001$ ). The mean prevalence is .243 (CI [.188; .306]; $p<.001$ ). The set of studies was heterogeneous for overall depression $(\mathrm{Q}=6526.54, \mathrm{p}<.001)$, suggesting differences in the effect sizes exist within this set of studies. Higgins' $I^{2} I^{2}$ showed that $99 \%$ of the variance comes
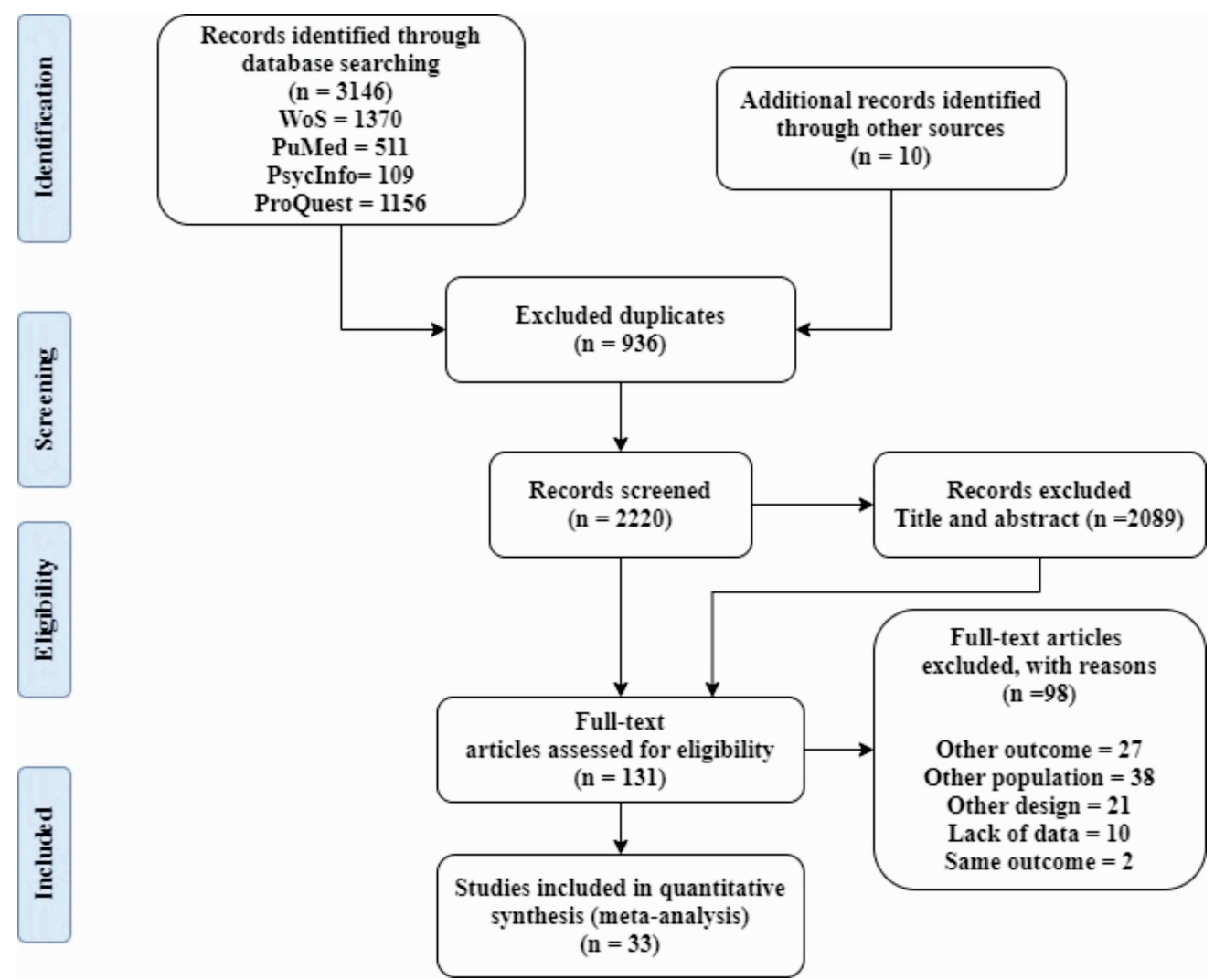

FIGURE 1. Prisma flow chart of study selection 
from a source other than sampling error. The variance of true effect sizes is $T^{2}=.901$ and the standard deviation of true effects is $\mathrm{T}=.949$ displayed in Table 2.

Severity, region and design moderators were entered into a meta-regression for their variance contribution to depression prevalence rates. The moderators were analyzed categorically to assess group differences in prevalence. The sources of the variation were investigated with bivariate analyses. Region was significantly associated with depression prevalence among physicians $\mathrm{Q}=17.72 ; \mathrm{p}<.00014$. The last 2 covariates severity and design could not be significantly associated with depression $(\mathrm{p}=$ .7728 ; respectively $\mathrm{p}=.2415$ ) suggesting that variation between sample allocation and the level of de-

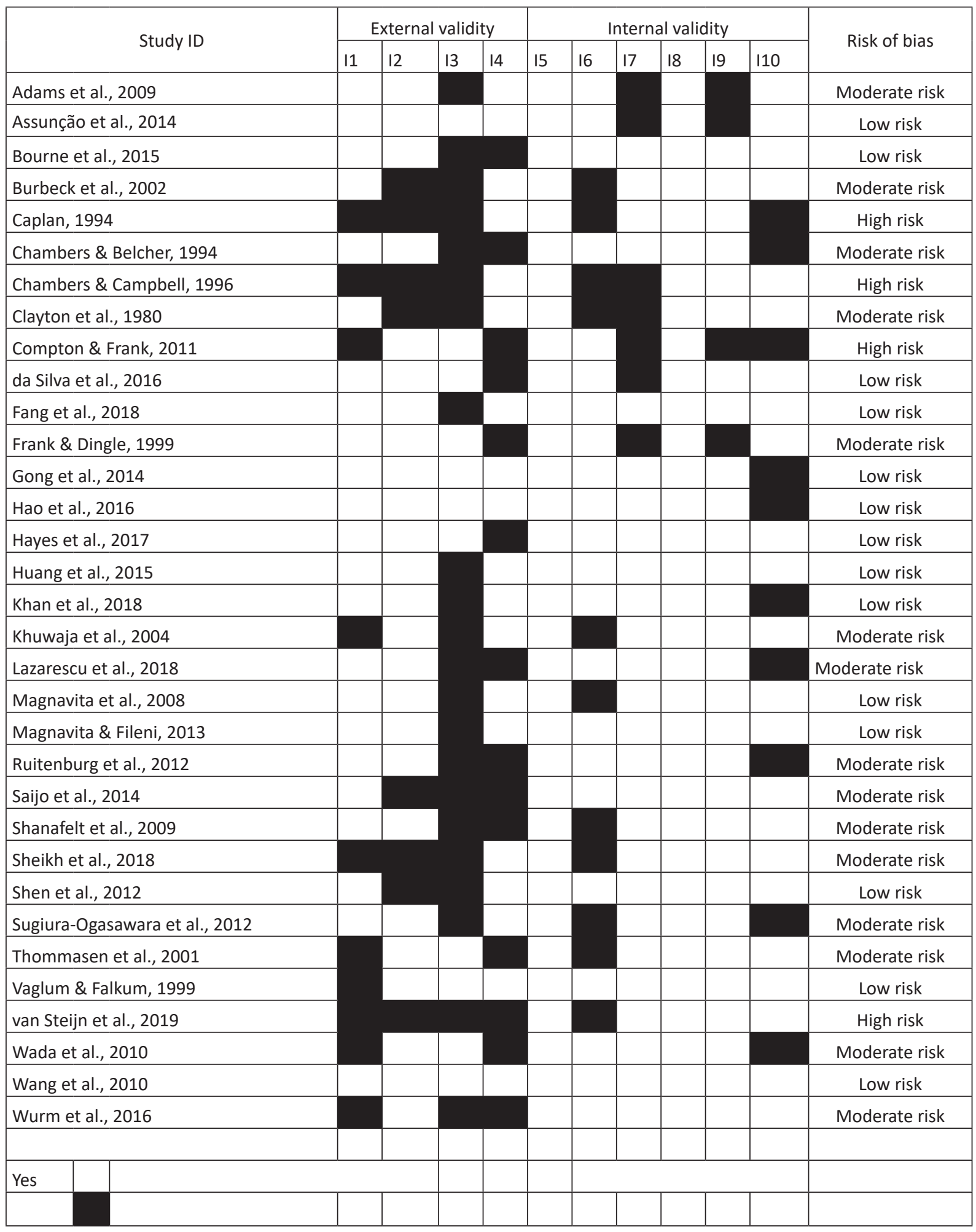

FIGURE 2. Risk of bias summary 


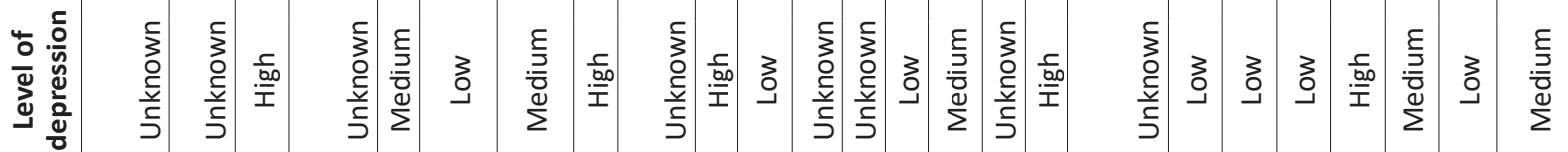

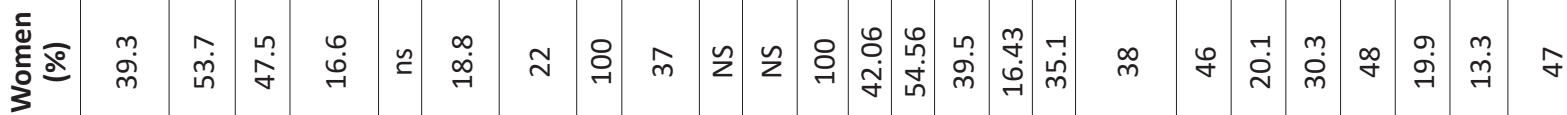

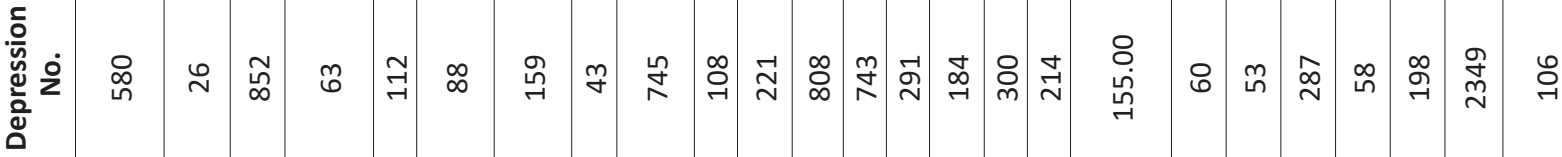

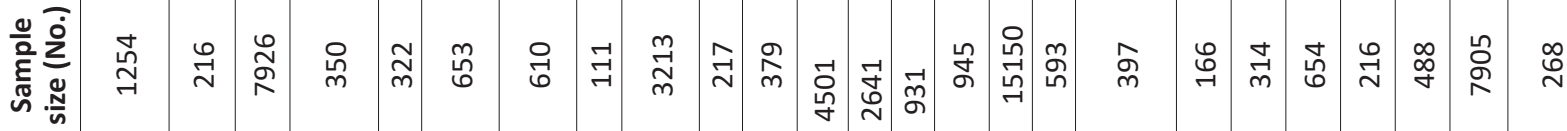

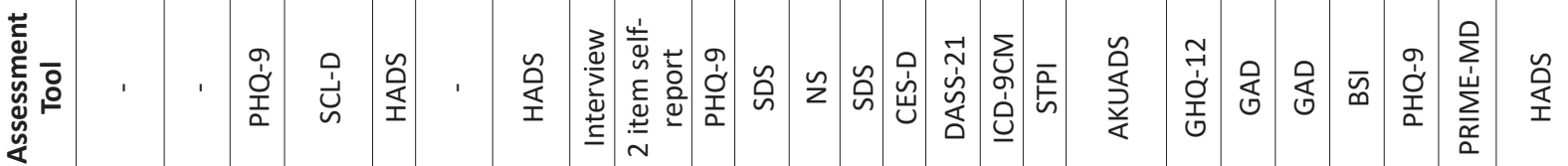

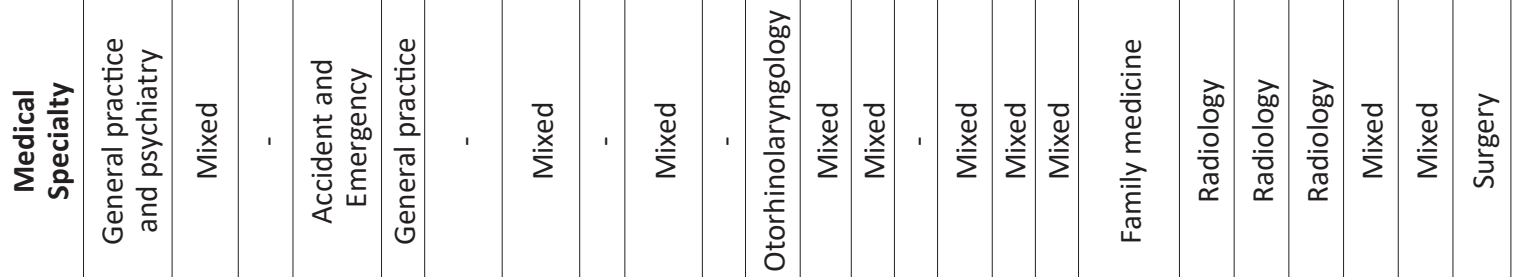

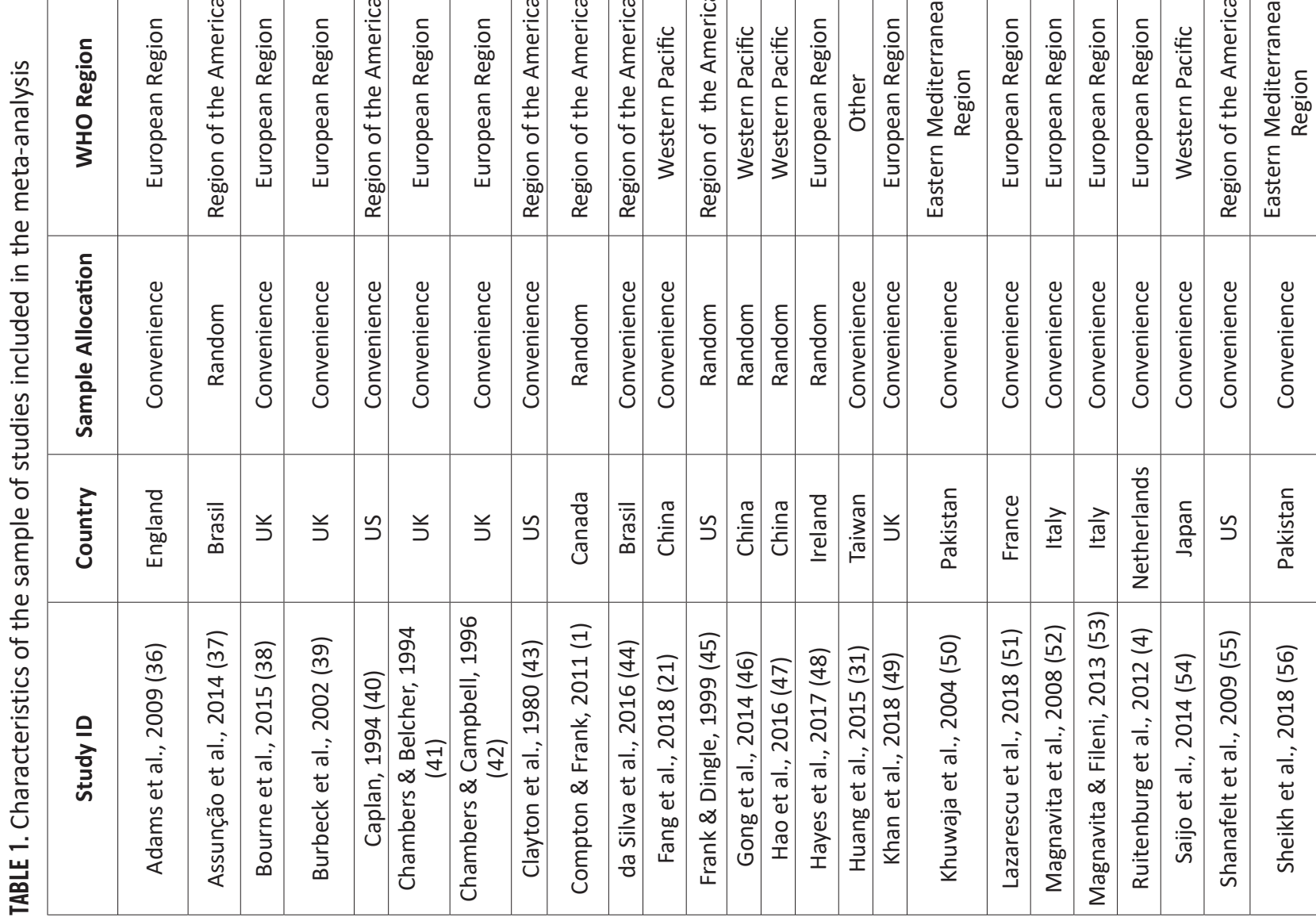




\begin{tabular}{|c|c|c|c|c|c|c|c|c|}
\hline 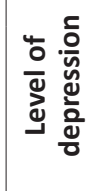 & $\begin{array}{l}\frac{E}{E} \\
\overline{\bar{z}} \\
\stackrel{\Xi}{\Delta} \\
\Sigma\end{array}$ & $\begin{array}{l}\frac{\xi}{\bar{J}} \\
\overline{\bar{y}} \\
\stackrel{0}{\Sigma}\end{array}$ & 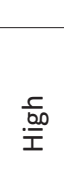 & $\begin{array}{l}\frac{\xi}{\bar{z}} \\
\overline{\bar{\theta}} \\
\stackrel{0}{\Sigma}\end{array}$ & \begin{tabular}{|l|}
$\frac{\xi}{3}$ \\
$\overline{\bar{z}}$ \\
$\stackrel{d}{\Sigma}$ \\
$\Sigma$
\end{tabular} & $\frac{\frac{c}{.000}}{\bar{I}}$ & $\begin{array}{l}\frac{\xi}{\bar{J}} \\
\overline{\bar{z}} \\
\stackrel{\omega}{\Sigma} \\
\Sigma\end{array}$ & $\frac{\frac{c}{000}}{\underline{\underline{I}}}$ \\
\hline 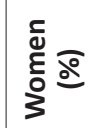 & $\begin{array}{l}\infty \\
\dot{0}\end{array}$ & $\begin{array}{l}\stackrel{+}{\Delta} \\
\dot{m}\end{array}$ & $\stackrel{\sim}{N}$ & $\check{c}$ & $\begin{array}{l}\dot{\theta} \\
\dot{\theta}\end{array}$ & $\stackrel{\grave{i}}{\stackrel{1}{n}}$ & $\begin{array}{l}0 \\
i \\
\text { in }\end{array}$ & $\begin{array}{l}\stackrel{\operatorname{n}}{f} \\
\stackrel{f}{2}\end{array}$ \\
\hline 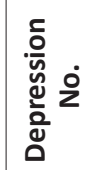 & $\stackrel{m}{\underset{\sim}{-}}$ & 움 & $\vec{\gamma}$ & ด̆ & $\hat{\imath}$ & $\underset{m}{\stackrel{9}{m}}$ & 离 & ô \\
\hline 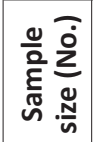 & 离 & $\begin{array}{l}\overrightarrow{0} \\
\vec{y}\end{array}$ & $\underset{\text { సి }}{ }$ & $\begin{array}{l}\infty \\
\infty\end{array}$ & 命 & $\begin{array}{l}\widetilde{W} \\
\text { O }\end{array}$ & $\begin{array}{l}\infty \\
\stackrel{\infty}{+} \\
\sim\end{array}$ & $\begin{array}{l}\hat{S} \\
\infty \\
\text { مी }\end{array}$ \\
\hline 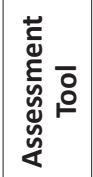 & $\tilde{n}$ & $\underline{\varphi}$ & $\overline{\mathrm{o}}$ & 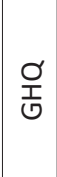 & 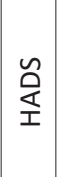 & $\begin{array}{l}\tilde{\hat{S}} \\
\tilde{\omega} \\
\stackrel{0}{\sigma}\end{array}$ & $\begin{array}{l}\text { 它 } \\
\text { 出 }\end{array}$ & $\overline{\bar{Q}}$ \\
\hline 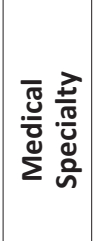 & 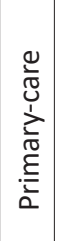 & 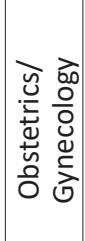 & 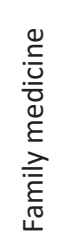 & $\begin{array}{l}\bar{D} \\
\dot{x} \\
\dot{\Sigma}\end{array}$ & 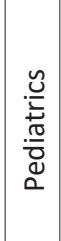 & $\begin{array}{l}\dot{0} \\
\dot{x} \\
\dot{x} \\
\Sigma\end{array}$ & $\begin{array}{l}\bar{d} \\
\dot{x} \\
\dot{\Sigma}\end{array}$ & י \\
\hline 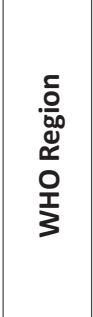 & 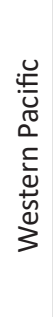 & 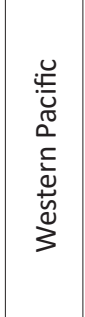 & 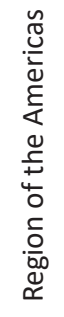 & 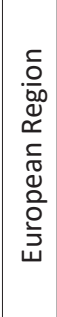 & 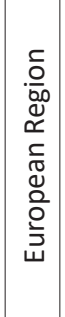 & 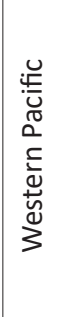 & 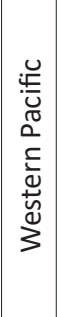 & 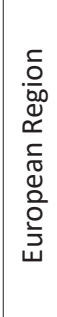 \\
\hline 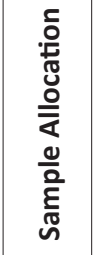 & 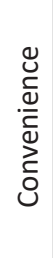 & 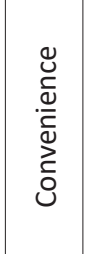 & $\begin{array}{l}\varepsilon \\
\frac{g}{0} \\
\frac{0}{c} \\
\mathbb{\pi} \\
\propto\end{array}$ & 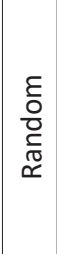 & 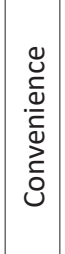 & 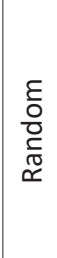 & 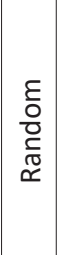 & 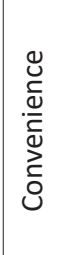 \\
\hline 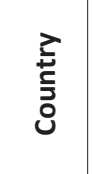 & : & $\begin{array}{l}\frac{\sqrt{0}}{0} \\
\frac{0}{00} \\
\frac{10}{n}\end{array}$ & $\begin{array}{l}\frac{\pi}{0} \\
\mathbb{0} \\
\mathbb{0} \\
0\end{array}$ & $\begin{array}{l}\text { ते } \\
3 \\
0 \\
2\end{array}$ & 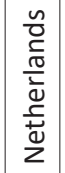 & $\begin{array}{l}\frac{1}{\sqrt{0}} \\
\frac{0}{0} \\
\sim\end{array}$ & 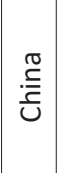 & $\begin{array}{l}\frac{\pi}{2} \\
\frac{2}{2} \\
\frac{2}{2}\end{array}$ \\
\hline 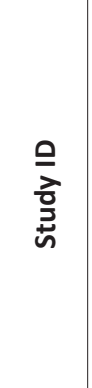 & 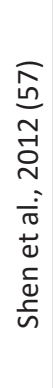 & 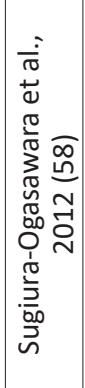 & 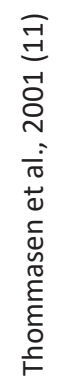 & 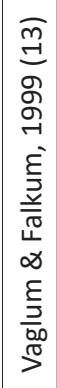 & 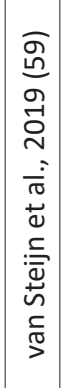 & $\begin{array}{l}0 \\
0 \\
0 \\
0 \\
0 \\
0 \\
0 \\
\dot{0} \\
0 \\
0 \\
0 \\
\frac{0}{0} \\
\tilde{0} \\
3\end{array}$ & 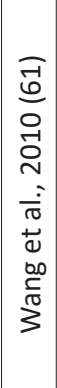 & 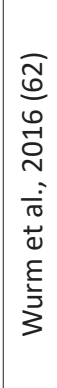 \\
\hline
\end{tabular}

pression did not explain the heterogeneity in the observed depression or depressive symptom prevalence estimates (Figure 4). The proportion of the true variation that is explained by the covariance is $\mathrm{R}^{2}=.3522$ (Table 3). That means the model can explain $35.22 \%$ of the variance between studies and $58.22 \%$ of the variance is the variance that can not be explained by the model. The region with the highest increment is region of Western Pacific $\left(\mathrm{R}^{2}=\right.$ .2681).

\section{DISCUSSIONS}

This is thought to be the first meta-analysis to investigate the prevalence of depression among physicians, others than residents, fellows or last year students. Using meta-analytical methods, we pooled the prevalence estimates of depression reported in 33 studies published between 1980 and 2019. The studies varied in terms of sample selection, level of depression, assessment tools, and nationality. The 33 studies selected for meta-analysis were geographically diverse and included 15 countries: 1 from Austria, 2 from Brazil, 2 from Canada, 5 from China, 6 from UK, 1 from France, from Ireland, 2 from Italy, 3 from Japan, 2 from Netherlands, 1 from Norway, 2 from Pakistan, 1 from Taiwan and 4 from USA. Prevalence rates for overall depression that were reported in studies included 10,978 individuals of 64,691 physicians.

This study has investigated two main questions: (1) what is the prevalence of depression among physicians, and (2) does region, level of depression or type of sampling selection influence the prevalence of depression? Our meta-analytical results indicate the pool prevalence of depression among physicians is $24.3 \%$. The current study is in line with other studies on the prevalence of depression $(3,24,63)$, aggregating prevalence data from various resources to obtain an overall prevalence estimate. The results were based on heterogeneous data.

It is important to note that the majority of the studies, participants were assessed through self-report inventories that measured depressive symptoms, the gold-standard of clinical diagnostic for major depressive disorder. On this line, the sensitivity and specificity of these instruments for diagnosing depression do not vary substantially.

The countries where depression is the most prevalent are China and Japan, this is in concordance with other studies $(63,64)$ and it is caused mostly by higher levels aggressiveness targeted on medical professionals, society stigmatization and relatively low remuneration, which may influence the mental health of physicians, expressed by depressive disorders $(21,47,65)$. On the other hand, In Japan the short number of days off, and the shifts 


\section{Meta-Analysis of depression prevalence}

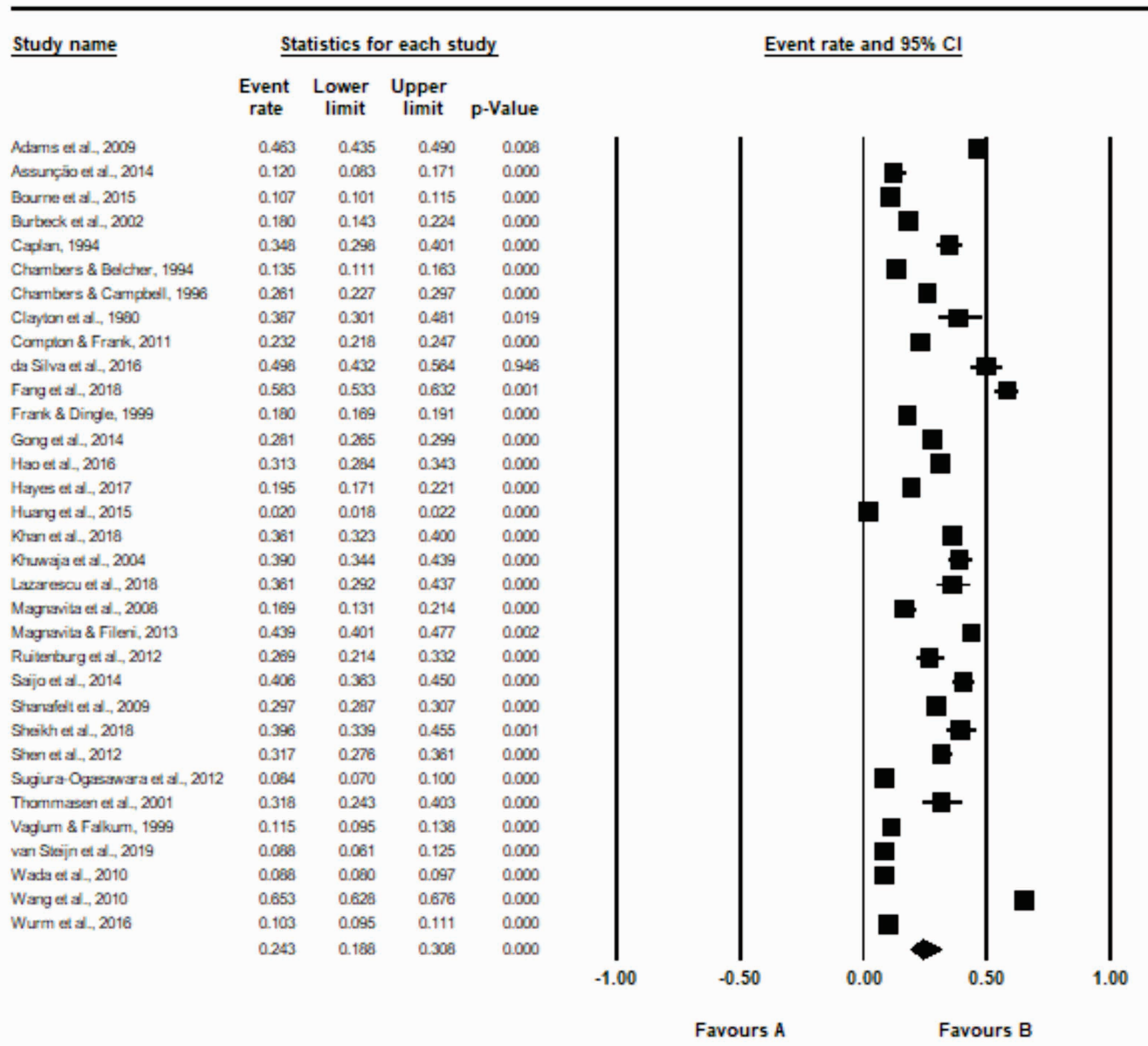

FIGURE 3. Standardized event rates and forest plot of all the studies sample

TABLE 2. The main meta-analytical results

\begin{tabular}{|c|c|c|c|c|c|c|c|c|c|c|c|c|c|c|}
\hline & & $\begin{array}{c}\text { ES } \\
(95 \% \mathrm{Cl})\end{array}$ & & & $\begin{array}{r}\text { Test } 0 \\
(2-1 \\
\end{array}$ & $\begin{array}{l}\text { f null } \\
\text { ail) }\end{array}$ & & Hete & ogeneity & & & $\begin{array}{c}\text { Tau } \\
\text { Squared }\end{array}$ & & \\
\hline Model & Studies & $\begin{array}{c}\text { Point } \\
\text { estimate }\end{array}$ & $\mathrm{LL}$ & UL & Z-value & P-value & Q-value & $\begin{array}{l}\mathrm{df} \\
\text { (Q) }\end{array}$ & P-value & $1^{2}$ & $\mathrm{Tau}^{2}$ & SE & Variance & Tau \\
\hline Fixed & 33 & 0.223 & 0.219 & 0.227 & -110.733 & 0.0000 & 6526.539 & 32 & 0.0000 & 99.510 & 0.901 & 0.363 & 0.132 & 0.949 \\
\hline Random & 33 & 0.243 & 0.188 & 0.308 & -6.822 & 0.0000 & & & & & & & & \\
\hline
\end{tabular}

TABLE 3. Statistics for the meta-regression model

\begin{tabular}{|c|c|c|c|c|c|c|c|}
\hline Test of the model & & & Goodness of Fit & & & & $\begin{array}{l}\text { Total between-study } \\
\text { variance }\end{array}$ \\
\hline $\mathrm{Q}$ - value & $\mathrm{P}$ - value & $\mathrm{Tau}^{2}$ & $\mathrm{Tau}$ & $\mathrm{I}^{2}$ & $\mathrm{Q}$ - value & $\mathrm{P}$ - value & $\mathrm{R}^{2}$ analog \\
\hline 20.56 & 0.0084 & 0.5837 & 0.764 & $99 \%$ & 2401.25 & 0.0000 & 0.3522 \\
\hline
\end{tabular}

Set

Covariate
Intercept
[legion: Eastern
Region: European Region
Region: Region of the
Region: Western Pacific
Severity: High
Severity: Low
Severity: Medium
Design: Random

Coefficient
-3.9020
3.4745
2.5519
3.1492
3.2030
-0.0431
0.3391
-0.0148
-0.4034

$\left.\begin{array}{lccrl}\begin{array}{l}\text { tandard } \\ \text { Error }\end{array} & \begin{array}{c}95 \% \\ \text { Lower }\end{array} & \begin{array}{c}\text { 95\% } \% \\ \text { Upper }\end{array} & \text { Z-value } & \begin{array}{l}\text { 2-sided } \\ \text { P-value }\end{array} \\ 0.7662 & -5.4037 & -2.4002 & -5.09 & 0.0000 \\ 0.9632 & 1.5867 & 5.3623 & 3.61 & 0.0003 \\ 0.8618 & 0.8629 & 4.2409 & 2.96 & 0.0031 \\ 0.8791 & 1.4261 & 4.8723 & 3.58 & 0.0003 \\ 0.9127 & 1.4140 & 4.9919 & 3.51 & 0.0004 \\ 0.4281 & -0.8822 & 0.7961 & -0.10 & 0.9198 \\ 0.4611 & -0.5646 & 1.2429 & 0.74 & 0.4621 \\ 0.4128 & -0.8238 & 0.7942 & -0.04 & 0.9714\end{array}\right] \quad Q=17.72, \mathrm{df}=4, \mathrm{p}=0.0014$

FIGURE 4. The impact of full meta-regression model 
spent in overnight work and on-call are one of the main causes of depression $(27,54,66)$ followed by low level of personal accomplishment (67).

Based on our study and compared with other groups of population, physicians have a higher prevalence of depression. These results indicate that the current status of mental health problems among physicians might have a negative impact on health care services and patient health-care. From a practical perspective our results bring an additional acknowledgment of the necessity of careful screening of and proper intervention in this mental health issue and should be implemented through medical institutions and facilitated by counselors in a timely and consistent manner.

Implications for future research are various. Although our literature search, found that previous studies about depression among physicians were mostly cross-sectional studies, future longitudinal investigations with dynamic study designs are highly recommended. Moreover, current studies on mental health problems among physicians mainly focus on depression, anxiety, burnout and stress. Future studies are needed to investigate other mental health problems, such as obsessive-compulsive disorder, bipolar disorder or combination of depression and other comorbidities. As well, it is needed to investigate depression with others counterproductive behaviors, including absenteeism and poor job performance or with accidents and errors and consumption of substances. In addition, more stratified and subgroup analyses are suggested in future research to investigate mental health problems in a more comprehensive manner. Finally, there is a lack of prevention or treatment studies using randomized controlled trial design.

\section{CONCLUSION}

Investment in developing and assessing interventions target in depression of physicians must be a public health priority to help to reduce the effect of wick medical services, patients complains and for a healthier medical professional worldwide.

\section{Conflict of interest: none declared Financial support: none declared}

\section{REFERENCES}

1. Compton MT, Frank E. Mental health concerns among Canadian physicians: results from the 2007-2008 Canadian Physician Health Study. Compr Psychiatry. 2011 Sep-Oct;52(5):542-7.

2. Harvey SB, Modini M, Joyce S, Milligan-Saville JS, Tan L, Mykletun A, Bryant RA, Christensen H, Mitchell PB. Can work make you mentally ill? A systematic meta-review of work-related risk factors for common mental health problems. Occup Environ Med. 2017 Mar;74(4):301-310.

3. Rotenstein LS, Torre M, Ramos MA, Rosales RC, Guille C, Sen S, Mata DA. Prevalence of Burnout Among Physicians: A Systematic Review. JAMA. 2018 Sep 18;320(11):1131-1150.

4. Ruitenburg MM, Frings-Dresen MH, Sluiter JK. The prevalence of common mental disorders among hospital physicians and their association with self-reported work ability: a cross-sectional study. BMC Health Serv Res. 2012 Aug 31;12:292-8.

5. Hem E, Grønvold NT, Aasland OG, Ekeberg O. The prevalence of suicidal ideation and suicidal attempts among Norwegian physicians. Results from a cross-sectional survey of a nationwide sample. Eur Psychiatry. 2000 May;15(3):183-9.

6. Tyssen R, Vaglum P, Grønvold NT, Ekeberg O. Suicidal ideation among medical students and young physicians: a nationwide and prospective study of prevalence and predictors. J Affect Disord. 2001 Apr; 64(1):69-79.

7. Voltmer E, Kieschke U, Spahn C. Work-related behaviour and experience patterns of physicians compared to other professions. Swiss Med Wkly. 2007 Aug 11;137(31-32):448-53.

8. Wallace JE, Lemaire JB, Ghali WA. Physician wellness: a missing quality indicator. Lancet. 2009 Nov 14;374(9702):1714-21.

9. Fahrenkopf AM, Sectish TC, Barger LK, Sharek PJ, Lewin D, Chiang VW, Edwards S, Wiedermann BL, Landrigan CP. Rates of medication errors among depressed and burnt out residents: prospective cohort study. BMJ. 2008 Mar 1;336(7642):488-91.

10. Waldman SV, Diez JC, Arazi HC, Linetzky B, Guinjoan S, Grancelli H. Burnout, perceived stress, and depression among cardiology residents in Argentina. Acad Psychiatry. 2009 Jul-Aug;33(4):296-301.

11. Thommasen HV, Lavanchy M, Connelly I, Berkowitz J, Grzybowski S. Mental health, job satisfaction, and intention to relocate. Opinions of physicians in rural British Columbia. Can Fam Physician. 2001 Apr;47:737-44.

12. Liu L, Chang Y, Fu J, Wang J, Wang L. The mediating role of psychological capital on the association between occupational stress and depressive symptoms among Chinese physicians: a cross-sectional study. BMC Public Health. 2012 Mar 21;12:219.

13. Vaglum P, Falkum E. Self-criticism, dependency and depressive symptoms in a nationwide sample of Norwegian physicians. J Affect Disord. 1999 Jan-Mar;52(1-3):153-9.

14. Bernburg M, Vitzthum K, Groneberg DA, Mache S. Physicians' occupational stress, depressive symptoms and work ability in relation to their working environment: a cross-sectional study of differences among medical residents with various specialties working in German hospitals. BMJ Open. 2016 Jun 15;6(6):e011369.

15. Estryn-Behar M, Doppia MA, Guetarni K, Fry C, Machet G, Pelloux P, Aune I, Muster D, Lassaunière JM, Prudhomme C. Emergency physicians accumulate more stress factors than other physicians-results from the French SESMAT study. Emerg Med J. 2011 May;28(5):397-410.

16. Givens JL, Tjia J. Depressed medical students' use of mental health services and barriers to use. Acad Med. 2002 Sep;77(9):918-21.

17. Hsu LKG. Dr. Hsu Replies. American Journal of Psychiatry. 1987;144(2):260-b-261.

18. Joules N, Williams DM, Thompson AW. Depression in resident physicians: a systematic review. Open Journal of Depression. 2014;3(3):89-100.

19. Williford ML, Scarlet S, Meyers MO, Luckett DJ, et al. MultipleInstitution Comparison of Resident and Faculty Perceptions of Burnout and Depression During Surgical Training. JAMA Surg. 2018 Aug 1;153(8):705-711.

20. Bourne T, De Cock B, Wynants L, Peters M, Van Audenhove C, Timmerman D, Van Calster B, Jalmbrant M. Doctors' perception of support and the processes involved in complaints investigations and how these relate to welfare and defensive practice: a cross-sectional survey of the UK physicians. BMJ Open. 2017 Nov 21;7(11):e017856.

21. Fang $H$, Zhao X, Yang H, Sun P, Li Y, Jiang K, Li P, Jiao M, Liu M, Qiao H, Wu Q. Depressive symptoms and workplace-violence-related risk 
factors among otorhinolaryngology nurses and physicians in Northern China: a cross-sectional study. BMJ Open. 2018 Jan 27;8(1):e019514.

22. Cai S, Lin H, Hu X, Cai YX, Chen K, Cai WZ. High fatigue and its associations with health and work related factors among female medical personnel at 54 hospitals in Zhuhai, China. Psychol Health Med. 2018 Mar;23(3):304-316.

23. He SC, Wu S, Wang C, Du XD, Yin G, Jia Q, Zhang Y, Wang L, Soares JC, Zhang XY. Interaction between job stress and the BDNF Val66Met polymorphism affects depressive symptoms in Chinese healthcare workers. J Affect Disord. 2018 Aug 15;236:157-163.

24. Mata DA, Ramos MA, Bansal N, Khan R, Guille C, Di Angelantonio E, Sen S. Prevalence of Depression and Depressive Symptoms Among Resident Physicians: A Systematic Review and Meta-analysis. JAMA. 2015 Dec 8;314(22):2373-83.

25. Center C, Davis M, Detre T, Ford DE, Hansbrough W, et al. Confronting depression and suicide in physicians: a consensus statement. JAMA. 2003 Jun 18;289(23):3161-6.

26. Krebs EE, Garrett JM, Konrad TR. The difficult doctor? Characteristics of physicians who report frustration with patients: an analysis of survey data. BMC Health Serv Res. 2006 Oct 6;6:128.

27. Wada K, Yoshikawa T, Goto T, Hirai A, Matsushima E, Nakashima Y, Akaho R, Kido M, Hosaka T. Association of depression and suicidal ideation with unreasonable patient demands and complaints among Japanese physicians: a national cross-sectional survey. Int J Behav Med. 2011 Dec;18(4):384-90.

28. Moher D, Liberati A, Tetzlaff J, Altman DG; PRISMA Group. Preferred reporting items for systematic reviews and meta-analyses: the PRISMA statement. Ann Intern Med. 2009 Aug 18;151(4):264-9, W64.

29. Hoy D, Brooks P, Woolf A, Blyth F, March L, Bain C, Baker P, Smith E, Buchbinder R. Assessing risk of bias in prevalence studies: modification of an existing tool and evidence of interrater agreement. J Clin Epidemiol. 2012 Sep;65(9):934-9.

30. Glossary: WHO Regions. Available at: https://www.greenfacts.org/ glossary/wxyz/who-regions.htm.

31. Huang CL, Weng SF, Wang JJ, Hsu YW, Wu MP. Risks of Treated Insomnia, Anxiety, and Depression in Health Care-Seeking Physicians: A Nationwide Population-Based Study. Medicine (Baltimore). 2015 Sep;94(35):e1323.

32. Borenstein $\mathrm{M}$, et al. Reporting the results of a meta-analysis. Introduction to meta-analysis, 1st ed. John Wiley and Sons, 2009; 365-70.

33. Borenstein M, Rothstein H, Cohen J. Comprehensive meta-analysis: A computer program for research synthesis. Englewood, NJ: Biostat, 1999.

34. Lipsey MW, Wilson DB. Practical meta-analysis. Sage Publications, Inc, 2001.

35. Borenstein M. Common mistakes in meta-analysis and how to avoid them. Biostat, Incorporated, 2019.

36. Adams EF, Lee AJ, Pritchard CW, White RJ. What stops us from healing the healers: a survey of help-seeking behaviour, stigmatisation and depression within the medical profession. Int I Soc Psychiatry. 2010 Jul;56(4):359-70.

37. Assunção AA, Machado CJ, Prais HA, de Araújo TM. Depression among physicians working in public healthcare in Belo Horizonte, Brazil. Soc Psychiatry Psychiatr Epidemiol. 2014 Aug;49(8):1219-29.

38. Bourne T, Wynants L, Peters M, Van Audenhove C, Timmerman D, Van Calster B, Jalmbrant M. The impact of complaints procedures on the welfare, health and clinical practise of 7926 doctors in the UK: a cross-sectional survey. BMJ Open. 2015 Jan 15;5(1):e006687.

39. Burbeck R, Coomber S, Robinson SM, Todd C. Occupational stress in consultants in accident and emergency medicine: a national survey of levels of stress at work. Emerg Med J. 2002 May;19(3):234-8.

40. Caplan RP. Stress, anxiety, and depression in hospital consultants, general practitioners, and senior health service managers. BMJ. 1994 Nov 12;309(6964):1261-3.

41. Chambers R, Belcher J. Predicting mental health problems in general practitioners. Occup Med (Lond). 1994 Sep;44(4):212-6.

42. Chambers R, Campbell I. Anxiety and depression in general practitioners: associations with type of practice, fundholding, gender and other personal characteristics. Fam Pract. 1996 Apr;13(2):170-3.
43. Clayton PJ, Marten S, Davis MA, Wochnik E. Mood disorder in women professionals. J Affect Disord. 1980 Mar;2(1):37-46.

44. da Silva AT, Lopes CS, Susser E, Menezes PR. Work-Related Depression in Primary Care Teams in Brazil. Am J Public Health. 2016 Nov; 106(11):1990-1997.

45. Frank E, Dingle AD. Self-reported depression and suicide attempts among U.S. women physicians. Am J Psychiatry. 1999 Dec; 156(12):1887-94.

46. Gong Y, Han T, Chen W, Dib HH, Yang G, Zhuang R, Chen Y, Tong X, Yin X, Lu Z. Prevalence of anxiety and depressive symptoms and related risk factors among physicians in China: a cross-sectional study. PLoS One. 2014 Jul 22;9(7):e103242.

47. Hao J, et al. Perceived organizational support impacts on the associations of work-family conflict or family-work conflict with depressive symptoms among Chinese doctors. International Journal of Environmental Research and Public Health. 2016;13(3):326.

48. Hayes B, Prihodova L, Walsh G, Doyle F, Doherty S. What's up doc? A national cross-sectional study of psychological wellbeing of hospital doctors in Ireland. BMJ Open. 2017 Oct 16;7(10):e018023.

49. Khan A, Teoh KR, Islam S, Hassard J. Psychosocial work characteristics, burnout, psychological morbidity symptoms and early retirement intentions: a cross-sectional study of NHS consultants in the UK. BMJ Open. 2018 Jul 23;8(7):e018720.

50. Khuwaja AK, Qureshi R, Azam SI. Prevalence and factors associated with anxiety and depression among family practitioners in Karachi, Pakistan. J Pak Med Assoc. 2004 Feb;54(2):45-9.

51. Lazarescu I, Dubray B, Joulakian MB, Blanchard P, et al. Prevalence of burnout, depression and job satisfaction among French senior and resident radiation oncologists. Cancer Radiother. 2018 Dec; 22(8):784-789.

52. Magnavita N, Fileni A, Magnavita G, Mammi F, Mirk P, Roccia K, Bergamaschi A. Work stress in radiologists. A pilot study. Radiol Med. 2008 Apr;113(3):329-46.

53. Magnavita N, Fileni A. Association of work-related stress with depression and anxiety in radiologists. Radiol Med. 2014 May;119(5):359-66.

54. Saijo Y, Chiba S, Yoshioka E, Kawanishi Y, et al. Effects of work burden, job strain and support on depressive symptoms and burnout among Japanese physicians. Int J Occup Med Environ Health. 2014 Dec;27(6):980-92.

55. Shanafelt TD, Balch CM, Bechamps GJ, Russell T, et al. Burnout and career satisfaction among American surgeons. Ann Surg. 2009 Sep;250(3):463-71

56. Sheikh MH, Waqas A, Naveed S, Shoaib M, Yousuf S, Butt SR, Tahir MH. Association of cognitive impairment with sleeping difficulties, anxiety and depression among Pakistani physicians. J Pak Med Assoc. 2018 Jun;68(6):932-935.

57. Shen LL, Lao LM, Jiang SF, Yang H, Ren LM, Ying DG, Zhu SZ. A survey of anxiety and depression symptoms among primary-care physicians in China. Int J Psychiatry Med. 2012;44(3):257-70.

58. Sugiura-Ogasawara M, Suzuki S, Kitazawa M, et al.; Japan Society of Obstetrics and Gynecology/Career Support Committee. Career satisfaction level, mental distress, and gender differences in working conditions among Japanese obstetricians and gynecologists. J Obstet Gynaecol Res. 2012 Mar;38(3):550-8.

59. van Steijn ME, Scheepstra KWF, Yasar G, Olff M, de Vries MC, van Pampus MG. Occupational well-being in pediatricians-a survey about work-related posttraumatic stress, depression, and anxiety. Eur J Pediatr. 2019 May;178(5):681-693.

60. Wada K, Yoshikawa T, Goto T, Hirai A, Matsushima E, Nakashima Y, Akaho R, Kido M, Hosaka T. National survey of the association of depressive symptoms with the number of off duty and on-call, and sleep hours among physicians working in Japanese hospitals: a cross sectional study. BMC Public Health. 2010 Mar 12;10:127.

61. Wang JN, Sun W, Chi TS, Wu H, Wang L. Prevalence and associated factors of depressive symptoms among Chinese doctors: a crosssectional survey. Int Arch Occup Environ Health. 2010 Dec; 83(8):905-11.

62. Wurm W, Vogel K, Holl A, Ebner C, Bayer D, et al. Depression-Burnout Overlap in Physicians. PLoS One. 2016 Mar 1;11(3):e0149913. 
63. Zeng W, Chen R, Wang X, Zhang Q, Deng W. Prevalence of mental health problems among medical students in China: A meta-analysis. Medicine (Baltimore). 2019 May;98(18):e15337.

64. Zhong X, Liu Y, Pu J, Tian L, Gui S, Song X, et al. Depressive symptoms and quality of life among Chinese medical postgraduates: a national cross-sectional study. Psychol Health Med. 2019 Sep;24(8):1015-1027.

65. Tang N, Thomson LE. Workplace violence in Chinese hospitals: the effects of healthcare disturbance on the psychological well-being of Chinese healthcare workers. International Journal of Environmental Research and Public Health 2019;16(19):3687.
66. Maruyama, Toru. Depressive symptoms and overwork among physicians employed at a university hospital in Japan. Journal of Health and Social Sciences, 2017;2(3):243-256.

67. Asai M, Morita T, Akechi T, Sugawara Y, Fujimori M, Akizuki N, Nakano T, Uchitomi Y. Burnout and psychiatric morbidity among physicians engaged in end-of-life care for cancer patients: a cross-sectional nationwide survey in Japan. Psychooncology. 2007 May;16(5):421-8. 